\title{
Intrathoracic Liver Heterotopia: An Incidental Finding at Autopsy
}

\author{
Shubha Padmanabha Bhat ${ }^{1}$ Aswathy Pradeep ${ }^{1}$ Kishan Prasad Hosapatna Laxminarayana ${ }^{1}$ Sajitha Kaliyat ${ }^{1}$ \\ Cherian Philemon Kurian ${ }^{2}$ Teerthanath Srinivas ${ }^{1}$
}

1Department of Pathology, K.S. Hegde Medical Academy, Nitte (Deemed to be University), Mangalore, Karnataka, India

${ }^{2}$ Department of Forensic Medicine, Dr. D.Y. Patil School of Medicine, Navi Mumbai, Maharashtra, India

\author{
Address for correspondence Shubha P. Bhat, MBBS, MD, \\ Department of Pathology, K.S. Hegde Medical Academy, \\ Nitte (Deemed to be University), Mangalore 575018, Karnataka, \\ India (e-mail: bhatshubha_257@rediffmail.com).
}

J Health Allied Sci ${ }^{\mathrm{NU}}$ 2020;10:46-48

\begin{abstract}
Keywords

- heterotopia

- intrathoracic

- liver

- autopsy

- histopathology

Heterotopia is the presence of a particular tissue at a nonphysiological site. The most common sites are gastric, pancreatic, and splenic heterotopias. While liver heterotopias are rare, intrathoracic heterotopias are much more limited. It is usually reported incidentally on imaging investigations or at autopsy. There is a high incidence of malignant transformation of heterotopic livers, and hence resection is always recommended. Here we report a case of heterotopic liver tissue in the right lung in a 42-yearold male, incidentally found at the gross examination of autopsy specimen of the lung.
\end{abstract}

\section{Introduction}

Heterotopia is the presence of a particular tissue at a nonphysiological site, usually coexisting with original tissue in its correct anatomical location. In other words, it implies ectopic tissue, in addition to the retention of the original tissue type. Common examples include gastric heterotopias in the ileum, pancreatic heterotopias in the stomach, and splenic heterotopias in gastrosplenic and splenorenal ligaments. ${ }^{1}$ Liver heterotopias have been reported in gall bladder, pancreas, adrenals, omentum, and umbilicus. Heterotopic liver tissue in the supradiaphragmatic region is exceedingly rare. Intrathoracically, it has been reported in lungs and pericardium. In the lungs, they are either attached via pedicle or appear as a nodule on the diaphragmatic surface. The incidence of heterotopia of the liver is found to be 1 in 2000 live births and intrathoracic heterotopic liver being even less. To date, only 23 cases of supradiaphragmatic liver heterotopia have been reported in the literature. ${ }^{2}$ Heterotopia of liver tissue has been reported in the fetal autopsy as early as 26 weeks of gestation. ${ }^{3}$ A male preponderance is seen. It is commonly found in the right hemithorax. They are usually asymptomatic in adults. Pediatric patients may present with respiratory distress and chest pain. When seen in the thoracic cavity, it is found incidentally on chest X-ray, during intrathoracic surgeries or at autopsy. The intrathoracic ectopic liver is usually associated with the congenital diaphragmatic defect, mimicking as lung mass on a computed tomography (CT) scan. Surgical intervention is required to establish the diagnosis and has been associated with excellent prognosis. ${ }^{3,4}$ Resection is always advised to prevent malignant transformation. Grossly, normal liver tissue is seen attached to the diaphragmatic surface of the lungs with or without a pedicle. The size of the heterotopic liver tissue can range from 0.3 to $12 \mathrm{~cm}$. Microscopy will usually show normal liver histology unless other pathological abnormalities are seen. ${ }^{3}$

Here, we report a case of heterotopic liver tissue in the right hilum of the lung incidentally found at the gross examination of autopsy specimen of the lung of a 42-year-old male with a history of sudden death.

\section{Case Report}

The body of a 42-year-old man, who was drowned, was brought to our forensic medicine and toxicology department. External examination showed that the body was of an adult male, thin built, and nourished, measuring $165 \mathrm{~cm}$ in length and weighing $45 \mathrm{~kg}$. Postmortem lividity was present in the back. Conjunctiva was congested, and oral mucosa and gums showed bluish discoloration. No external injuries were noted on the body. A medicolegal autopsy was performed. The brain weighed $1,180 \mathrm{~g}$ and showed multiple petechial
DOI https://doi.org/

10.1055/s-0040-1712329

ISSN 2582-4287.
License terms

(우 (1) $\Theta \circledast$ 
hemorrhages. Right lung weighed $465 \mathrm{~g}$ and left lung weighed $735 \mathrm{~g}$ both oozed blood-stained frothy fluid. The stomach weighed $255 \mathrm{~g}$ and had brown-colored mucoid fluid with fruity odor in it. The liver weighed 1,015 $\mathrm{g}$ and appeared softened and intact. Spleen weighed $115 \mathrm{~g}$ and seemed to be soft and pulpy. Both the kidneys, heart, esophagus, and other organs seemed to be unremarkable.

Whole heart, a portion of both right and left lungs, a part of the liver, a piece of right and left kidney, esophagus, and spleen were sent for histopathological examination. Pathologist was requested to look for myocarditis, coronary block, cardiomyopathy in the heart, tuberculosis, lung abscess, pneumonia in lungs, cirrhosis in the liver, acute tubular necrosis, and chronic pyelonephritis in the kidney, varices in esophagus, and malaria in the spleen.

Grossly, both the right and left lungs were spongy and showed anthracotic pigments. Emphysematous changes were seen toward the periphery. The outer surface of the right lung showed a nodular tissue measuring $5 \times 3.5 \times 3 \mathrm{~cm}$ attached to the right hilum on the mediastinal surface. It had a stalk measuring $0.8 \mathrm{~cm}$ in length (-Fig. 1). The cut surface of the nodule showed normal-appearing liver tissue ( $\boldsymbol{- \text { Fig. }}$ 2). The heart and both the kidneys were unremarkable. The liver showed a nutmeg appearance. Spleen showed areas of congestion and hemorrhage. Esophagus showed ulceration in its mucosa.

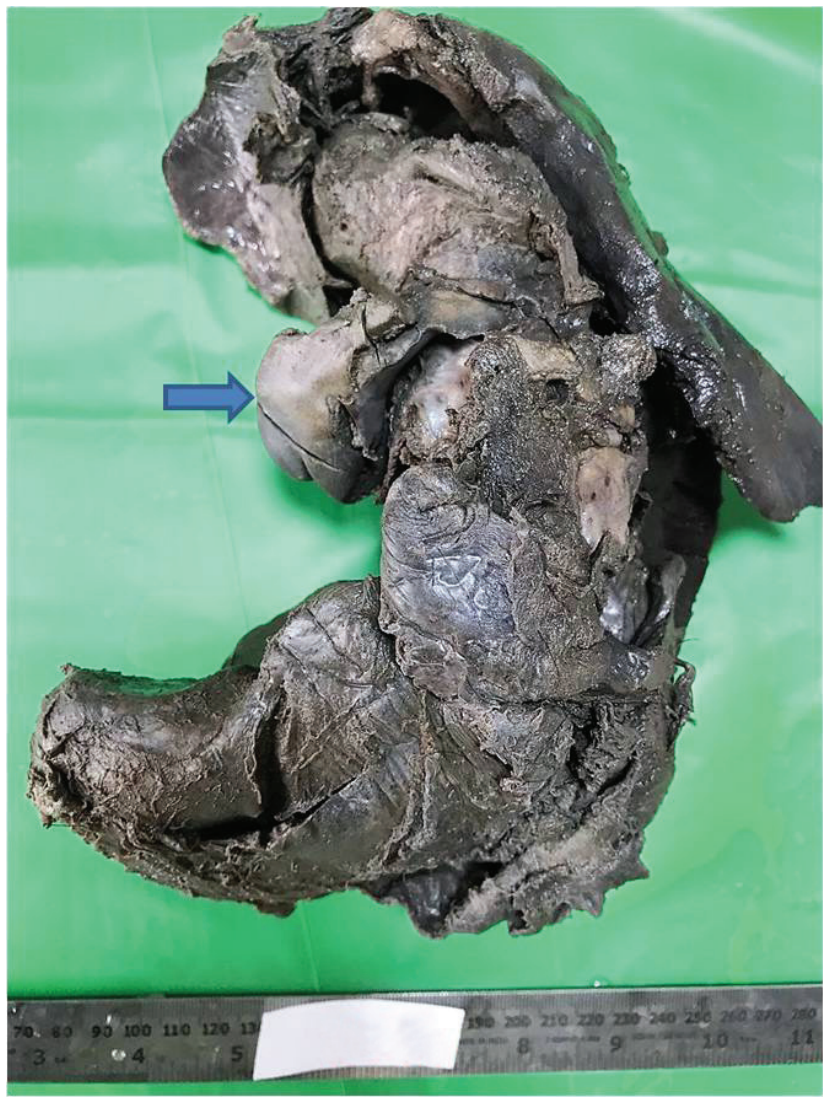

Fig. 1 Gross specimen of right lung showed a nodular tissue measuring $5 \times 3.5 \times 3 \mathrm{~cm}$ attached to the right hilum on the mediastinal surface corresponding to the middle lobe (arrow mark pointing to the liver tissue).

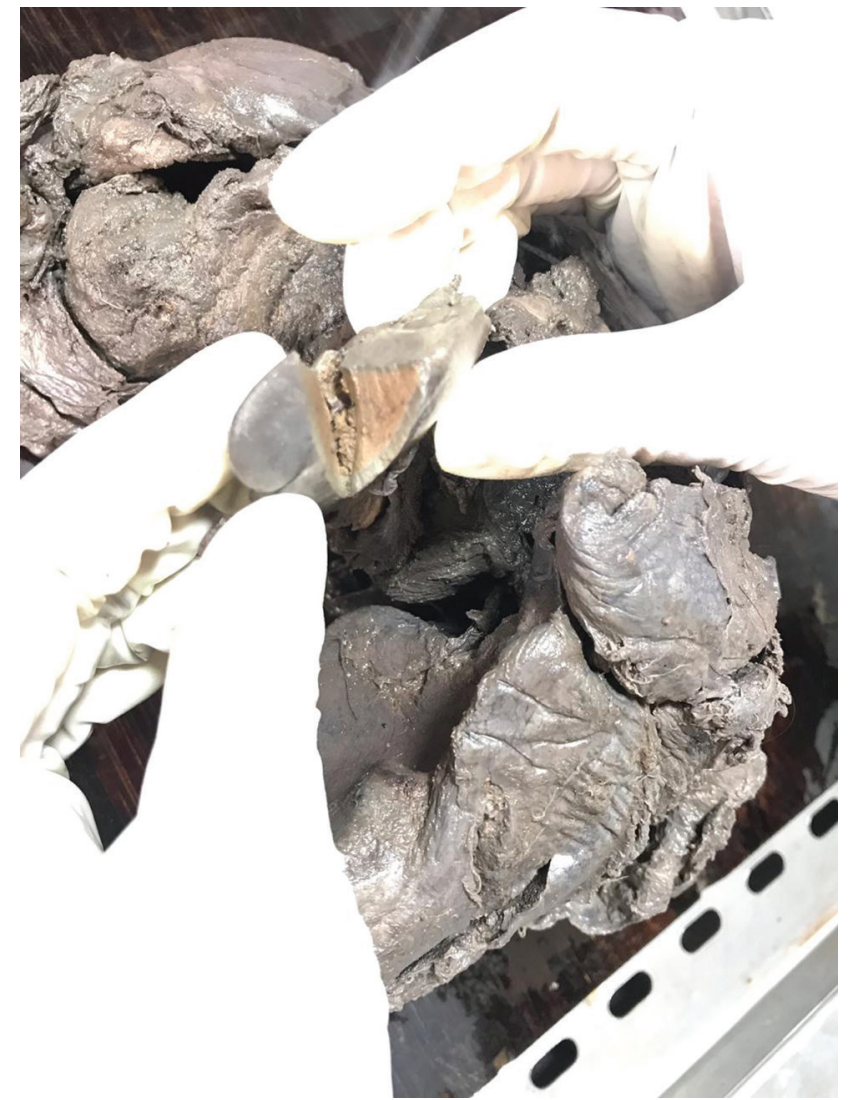

Fig. 2 Cut surface of the nodule showing normal-appearing liver tissue.

Microscopically, both the lung tissue showed alveoli, distended by edema fluid. A large area of alveolar hemorrhage and emphysematous changes was seen. Features were consistent with acute pulmonary congestion with pulmonary hemorrhage. The nodular tissue attached to the right lung hilum showed heterotopic liver tissue with no pathological abnormalities ( - Fig. 3). The liver showed dilated and congested central vein and sinusoids with centrilobular hemorrhagic necrosis and fatty change; features were consistent with chronic venous congestion. Spleen showed thickened capsule and trabeculae with red pulp showing congestion. The esophagus showed features consistent with varices. Heart showed endocardial fibrosis, with mitral and tricuspid valves showing myxoid degeneration, and both kidneys were unremarkable.

\section{Discussion}

Heterotopia of the liver is an uncommon condition with an incidence of 1 in 2,000 live births. It is most commonly found in gall bladder, pancreas, adrenals, omentum, and umbilicus. Collan et al classified heterotopic livers into four types: (1) an accessory lobe of the liver of considerable size and with a connecting stalk to the liver, (2) a small accessory lobe of the liver attached to the liver, (3) ectopic liver located without connection to the liver, and (4) microscopic ectopic liver tissue. 3

Twenty-three cases of intrathoracic lung tissue are reported to date in the literature. A male preponderance is observed with 


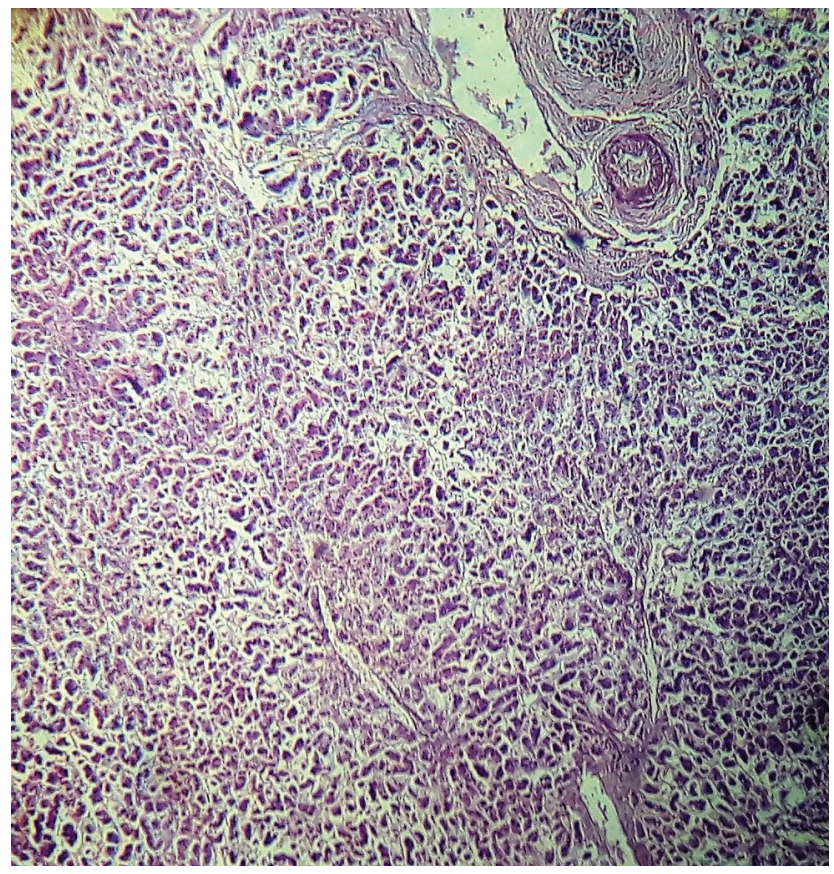

Fig. 3 Microscopy of nodule showed heterotopic liver tissue with normal histomorphology, hematoxylin and eosin, 10x.

a male to female ratio of $1.43: 1 .^{3}$ Intrathoracically, it has been reported in lungs and pericardium. In the lungs, it is most commonly found in the diaphragmatic and mediastinal surface.

The intrathoracic ectopic liver is usually asymptomatic in adults and is found incidentally on a chest X-ray as a radiopaque mass, or during intrathoracic surgeries, or at autopsy. In our case, it was found incidentally in the gross examination of autopsy specimen in the right hilum of the lung of a 42 -year-old male with a history of sudden death. ${ }^{6}$

The embryological development of the lung and liver is closely related. Both are derived from the endodermal layer. In a week-old embryo, the respiratory diverticulum arises from the ventral wall of the foregut to form the lung buds, and the hepatic diverticulum develops from the caudal part of the foregut. The hepatic diverticulum consists of rapidly proliferating cell strands that penetrate the septum transversum. Septum transversum develops into the central tendon of the diaphragm. The developing lungs and liver are close until the eighth week of gestation. ${ }^{3}$ There are two possible causes for an intrapulmonary ectopic liver. An accessory liver bud might develop near the lung buds and fuse with it or the development of an accessory liver bud independent of the main hepatic diverticulum. ${ }^{6.7}$

As patients with intrathoracic liver heterotopia are usually asymptomatic, it is difficult for clinicians to detect this condition before surgical intervention. When intraabdominal, occasionally, they may cause abdominal pain due to recurrent torsion or compression of adjacent organs. They may appear as a lung mass on chest X-ray and CT. Due to the small size of the most heterotopic liver and lack of awareness of this unusual condition, radiologists tend to miss this lesion., ${ }^{8,9}$

The heterotopic liver has been associated with malignancies more often than with benign lesions. They appear to have a normal architecture, but may not be functional metabolically, and this may facilitate carcinogenesis. It also has increased neoplastic potential compared with orthotopic liver tissue. This might have given rise to the hypothesis that heterotopic livers are particularly predisposed to the development of hepatocellular cancer. Several studies have found that ectopic liver does not have a complete vasculature or ductal system, unlike a healthy liver. Also, altered hepatic function may lead to chronic inflammation and cirrhosis, thus increasing the risk of developing Hepatocellular carcinoma. Hence, surgical excision is always recommended. ${ }^{9}$

Grossly they appear as a nodule, ranging in size from 0.3 to $12 \mathrm{~cm} .^{3}$ It seems to be most commonly attached to the mediastinal surface. The cut surface of the nodule is homogenous, solid, brown with a well-defined fibrous capsule. In our case, it was a nodular tissue arising from the mediastinal surface of the right lung attached by a pedicle. The cut surface showed normal-appearing liver tissue.

Microscopically, the nodule shows normal liver tissue consisting of hexagonal hepatocytes or may show features of associated pathological conditions, if any, like cirrhosis or hepatocellular carcinoma. In our case, histopathology of the nodule in the lung showed normal morphology of the liver. ${ }^{10}$

\section{Conclusion}

Intrathoracic ectopic liver tissue is very rare, but it should be taken into consideration as a differential diagnosis of a supradiaphragmatic mass. Awareness of this entity is necessary, which will help in the right preoperative and intraoperative or autopsy diagnosis. The microscopic examination should be performed to rule out associated pathological conditions, in particular, hepatocellular carcinoma. Hence, resection is always recommended.

\section{References}

1 Desmet VJ, Rosai J. Liver: Non-neoplastic lesions, tumor and tumor-like conditions. In: Roasi J, ed. Rosai and Ackerman's Surgical Pathology. 10th ed. Philadelphia: Elsevier; 2011:858-891

2 Chen YY, Huang TW, Chang H, Hsu HH, Lee SC. Intrathoracic caudate lobe of the liver: a case report and literature review. World J Gastroenterol 2014;20(17):5147-5152

3 An J, Han J, Lee KS, Choi YS. Supradiaphragmatic heterotopic liver presenting as a pleural mass: a case report. Tuberc Respir Dis (Seoul) 2010;69:191-195

4 Iber T, Rintala R. Intrapulmonary ectopic liver. J Pediatr Surg 1999;34(9):1425-1426

5 Collan Y, Hakkiluoto A, Hästbacka J. Ectopic liver. Ann Chir Gynaecol 1978;67(1):27-29

6 Lee SG, Ryu DS, Park MS. Kang CH, Choi SJ, Shin DR. J Korean Soc Radiol 2016;74(6):399-402

7 Lee SG, Ryu DS, Park MS, Kang CH, Choi SJ, Shin DR. A case of intrathoracic ectopic liver in a patient without diaphragmatic defect. J Korean Soc Radiol 2016;74(6):399-402

8 Arakawa M, Kimura Y, Sakata K, Kubo Y, Fukushima T, Okuda K. Propensity of ectopic liver to hepatocarcinogenesis: case reports and a review of the literature. Hepatology 1999;29(1):57-61

9 Huang W, Xu X, Li T, Zhang H, Chen Y, Li S. Ectopic liver tissue in stomach paries: a case report. Int J Clin Exp Pathol 2015;8(9):11704-11707

10 Leone N, De Paolis P, Carrera M, et al. Ectopic liver and hepatocarcinogenesis: report of three cases with four years' follow-up. Eur J Gastroenterol Hepatol 2004;16(8):731-735 